\title{
A QUANTITATIVE DEFENSE OF STABILIZATION POLICY
}

\author{
Darrel Cohen \\ Division of Research and Statistics \\ Federal Reserve Board \\ Washington, D.C. 20551
}

June 2000

\begin{abstract}
In an analysis of the value of growth and stabilization of consumption, Robert Lucas (1987) presents a stunning set of calculations implying that a permanent increase in the growth rate of consumption of only one-tenth percentage point per year is worth nearly 50 times as much to consumers as complete elimination of consumption variability. This is because the higher growth of consumption is worth a lot while the reduced variability is worth virtually nothing (at least in the post-war United States). Taken at face value, such a result supports the pursuit of feasible growth policies but calls into serious question the study and practice of macroeconomic stabilization policy even if complete elimination of variance were feasible and costless. Primarily by considering alternative meanings of stabilization that allow an increase in mean consumption, this paper establishes that stabilization can be worth a lot, at least 25 times the value found by Lucas. Further, the paper shows the value of a permanent increase in the growth rate of consumption to be only one-fourth the value in Lucas (although still relatively large), by deriving a modified valuation formula that allows the coefficient of relative risk aversion to exceed unity.
\end{abstract}

I thank Bill Cleveland, Bill English, Glenn Follette, David Lebow, Robert Lucas, John Roberts, Jeremy Rudd, Dan Sichel, and Wolf Ramm for their helpful comments and suggestions. The views expressed in this paper are those of the author alone and do not necessarily reflect those of the Board of Governors of the Federal Reserve System or other members of its staff. 
A Quantitative Defense of Stabilization Policy

\section{Introduction}

How much would it be worth to costlessly eliminate all business cycles or indeed cycles of any frequency, thereby generating an absolutely smooth path of consumption? How much is it worth to costlessly boost the growth rate of consumption even by a small amount? In responding to these questions, Robert Lucas (1987) presents a stunning set of calculations implying that a permanent increase in the growth rate of consumption of only one-tenth percentage point per year is worth nearly 50 times as much to consumers as complete elimination of consumption variability. This is because the higher growth of consumption is worth a lot, while the reduced variability is worth virtually nothing. ${ }^{1}$ Taken at face value, such a result supports the pursuit of feasible growth policies but calls into serious question the study and practice of macroeconomic stabilization policy--even if complete elimination of variance were feasible and costless. Of course, actual growth and stabilization policies must carefully consider issues of feasibility and cost. For example, as noted in the long-standing debate on policy activism, any attempt by policymakers to actively stabilize the macroeconomy may be unsuccessful for many reasons including expectational factors and lags in recognition, implementation, and impact.

The Lucas results are based on only a minimal number of assumptions. A representative consumer maximizes the expected present discounted value of utility of consumption.

Preferences are of the constant relative risk aversion form: $U\left(c_{t}\right)=c_{t}^{\gamma} / \gamma$ where $\gamma=(1-r)$, and $r$ is the coefficient of relative risk aversion. Capital markets are complete in the sense that households can perfectly insure against uncorrelated idiosyncratic income risk, and, thus, the only risk facing households is aggregate (correlated) risk. Consumption is a lognormally distributed process: $c_{t}=(1+g)^{t}\left(\exp \left(-\sigma^{2} / 2\right)\right) z_{t}$ where $\ln z_{t}$ is normally distributed with mean zero

1 It should be noted that Lucas does not claim that economic instability is not a problem under all possible conditions. Indeed, he considers the sensitivity of his results to alternative values in key parameters, in particular, the coefficient of relative risk aversion and the variance of log consumption. While large enough values of either parameter can put the cost of consumption instability on the radar screen, Lucas is quite explicit in concluding that instability is a "minor problem" in the post-war United States. 
and variance $\sigma^{2}$, and $\left\{z_{t}\right\}$ is a stationary process. Given the properties of lognormal variables, $\mathrm{Ec}_{\mathrm{t}}=(1+\mathrm{g})^{\mathrm{t}}$ (so g gives the constant deterministic growth rate of the expected value of consumption); also g and $\sigma^{2}$ are independent, so a reduction in variance has no effect on the mean of consumption. There is no model or mechanism to generate business cycles or growth; put another way, the existence of consumption variability and growth is specified exogenously.

Subsequent work has focused on the robustness of the result that there is virtually no utility gain from the elimination of consumption variance; in particular, the implications of alternative utility functions and incomplete markets for risk sharing have been developed. It is probably not unfair to say that on the whole this work has not led to a substantial modification of the original Lucas stabilization result, as a brief summary of the key findings of this work makes clear.

One might expect that because the marginal utility of consumption for each person is more variable in a world with incomplete insurance markets, the gains from stabilization policy would be greater in such a world provided that the policy allowed for smoother consumption streams. Along these lines, Ayse Imrohoroglu (1989) calculates the costs of business cycles in the presence of exogenously given idiosyncratic risk and incomplete insurance markets--in the form of various limitations on borrowing--that focuses on unemployment risk as the individual risk that would be affected by stabilization policy. She finds the welfare costs of aggregate fluctuations can be either larger or smaller than those computed by Lucas (the specific result depends on the exact specification), although the estimates are all fairly small. Andrew Atkeson and Christopher Phelan (1994) also develop a model of unemployment risk and incomplete markets, but one in which elimination of the correlation across individuals in this risk may lead individuals to choose greater idiosyncratic employment risk. In contrast to Imrohoroglu, they find that the gain from successful countercyclical policy is essentially zero; that is, it is even smaller in the world of incomplete markets than in a world of complete markets.

Other economists have examined the welfare cost implications of alternative utility functions. Christopher Otrok (1998) summarizes much of this work. Alternative preference specifications potentially can lead to much larger welfare gains from stabilization than those found by Lucas. However, the gains in fact are about the same size as those found in Lucas if the 
alternative (specifically, time-non-separable) preferences are chosen, along with a calibrated real business cycle model, so as to generate aggregate fluctuations in income and consumption similar to those observed in the U.S. data.

Finally, stepping further outside of the Lucas framework, others have conjectured the possibility of huge gains from stabilization, although no explicit quantification is provided. For example, Alan Blinder (1987) argues that national election outcomes depend on the state of the business cycle; further, cyclical downturns may have psychological and sociological costs. We would add that deep enough downturns could affect the very cohesiveness of societies. James Tobin (1994) offers the possibility that the growth rate of capacity itself is reduced by large and prolonged departures of output from potential because they adversely and irreversibly affect aggregate investment in physical capital and the stock of human capital. ${ }^{2}$ Further, Tobin and Christina Romer (1999) both note that the apparent reduction in macroeconomic variability between the pre-World War II and post-World War II periods may be attributable to countercyclical policies; it follows that elimination of stabilization policy might cause a large enough increase in aggregate variance to alter the Lucas quantitative result.

This paper, however, maintains the Lucas central assumptions about the form of the utility function, the completeness of markets, and the stochastic process driving consumption. Nevertheless, much smaller--although still sizable--gains from a higher growth rate of consumption and substantially larger gains for macroeconomic stabilization are found. The smaller gain from higher growth rates results from allowing the coefficient of relative risk aversion to exceed the value of unity implicitly used by Lucas. The key reason for the larger gains from stabilization found here is that the meaning of stabilization is different.

Whereas the Lucas stabilization exercise would eliminate both above-trend and belowtrend fluctuations in consumption, here we consider stabilization that eliminates only (some or all

2 Based on the literature on the relationship between physical investment and uncertainty, it is not obvious that a reduction in variance would necessarily increase capital investment; see, for example, Ricardo Caballero (1999). 
of) the below-trend movements, thus allowing an increase in mean consumption. ${ }^{3}$ While generating interesting new quantitative results, this approach is not entirely satisfactory because elimination of below-trend movements ceteris paribus would generate a new average line and hence new below-average movements in a world of symmetric variations of log consumption about trend. To address this issue, we consider a "plucking" model in which economic activity either is at capacity or is plucked below capacity, or alternatively, in which economic activity represents asymmetrical departures from full-employment equilibrium. We again find a significant value to eliminating variation in this model. Indeed, using the same parameter values as Lucas, we find that in either framework complete elimination of negative deviations of consumption (from trend or capacity) is worth at least as much to consumers as a permanent increase in the growth rate (g) of consumption of about two-tenths percentage point per year.

The rest of the paper is structured as follows. Section II derives the value of elimination of some (or all) below-trend movements in aggregate consumption. Section III derives the same value in a "plucking-like" model of economic activity, utilizing a new result for truncated lognormal distributions. Section IV re-opens the issue of the value of increasing the growth rate of consumption. Section V concludes.

\section{The Value of Eliminating Below-Trend Consumption Movements}

Lucas establishes analytically that the value (compensating variation) of complete elimination of the variance of aggregate consumption--that is, elimination of above-trend as well as below-trend movements of consumption--is given by $\lambda_{\mathrm{L}}=\mathrm{r}^{2} / 2$. Lucas sets $\sigma=.013$ in accord with U.S. data on real personal consumption expenditures for the post-war period through $1980{ }^{4}$

3 The possibility of filling in troughs without shaving off peaks has previously been considered in the literature, although it has focused on GDP rather than consumption; for example, see J. Bradford DeLong and Lawrence Summers (1988).

${ }^{4}$ Based on quarterly consumption data released as part of the 1999 benchmark revisions to the National Income and Product Accounts, the standard deviation of the difference between the $\log$ of real personal consumption expenditures and its trend remains at .013 for the period 1947 to 1999 . Arguably, the underlying theory is more applicable to non-durables consumption expenditures. The corresponding standard deviation for the log of real personal consumption expenditures excluding durables is .009 for the post-war period. For both measures of consumption, the trend values are based on the Hodrick-Prescott filter. The standard deviations 
With a coefficient of relative risk aversion of $5(=r)$, the value of variance elimination is equivalent to an increase in consumption, uniform across all dates and values of the shocks, of only .04 percentage point $\left(\lambda_{\mathrm{L}}=.0004\right)$. Other reasonable values of $\mathrm{r}$ also yield very small costs of consumption instability in this framework.

Now a somewhat different question is considered. What is the value to consumers of eliminating some or all of below-trend movements in aggregate consumption, in effect eliminating some portion (or all) of each recession but not eliminating above-trend performance? Since the random component of consumption is drawn from a lognormal distribution, this question amounts to asking consumers to value a truncation of the left portion of the lognormal and associated normal distributions. For example, elimination of all consumption variation below the mean value, $(1+\mathrm{g})^{\mathrm{t}}$, requires a policy that perfectly offsets all random draws below the zero mean of the normally distributed log consumption or equivalently all draws below the median $\left(=\mathrm{e}^{\mu}=1\right)$ of the lognormally distributed consumption. Proposition 1 below provides a general result about the value of truncations; its proof depends crucially on the following lemma (proven in the Appendix).

\section{Lemma 1}

If $\ln \mathrm{z} \sim \mathrm{N}\left(\mu, \sigma^{2}\right)$ and is truncated from below at $\ln \mathrm{z}_{0}$ (i.e., if the distribution of $\ln \mathrm{z}$ below $\ln z_{0}$ is removed), and if $\Phi($.$) denotes the standard normal distribution function, then$

$$
\begin{aligned}
E\left(z^{j}\right) & =(j \text { th moment of } z \text { about zero if not truncated }) \times\left\{\left(1-\Phi\left(\Delta_{0}-j \sigma\right)\right) /\left(1-\Phi\left(\Delta_{0}\right)\right\}\right. \\
& =\exp \left[j \mu+\mathrm{j}^{2} \sigma^{2} / 2\right] \times\left\{\left(1-\Phi\left(\Delta_{0}-\mathrm{j} \sigma\right)\right) /\left(1-\Phi\left(\Delta_{0}\right)\right\},\right.
\end{aligned}
$$

where $\Delta_{0}=\left(\ln z_{0}-\mu\right) / \sigma$.

\section{Proposition 1}

$\infty$

Following Lucas, suppose consumers maximize $E\left\{\Sigma \beta^{t} U\left(c_{t}\right)\right\}$ where $U\left(c_{t}\right)=c_{t}^{\gamma} / \gamma$ and $\mathrm{t}=0$

$\beta \in(0,1)$ denotes the discount factor. Also assume that $\mathrm{c}_{\mathrm{t}}=(1+\mathrm{g})^{\mathrm{t}}\left(\exp \left(-\sigma^{2} / 2\right)\right) \mathrm{z}_{\mathrm{t}}$ where $\ln \mathrm{z}_{\mathrm{t}} \sim$ $\mathrm{N}\left(0, \sigma^{2}\right)$. The value (compensating variation) to an individual of truncating the distribution of

roughly double in magnitude if trend is determined as the fitted value from a regression of log consumption on a constant and a linear time trend (with an allowance for a change in intercept and slope occurring in 1973). 
$\ln \mathrm{z}$ below $-\mathrm{k} \sigma, \mathrm{k} \geq 0$, is given by:

$\lambda_{1}=\{\Phi[\mathrm{k}+\gamma \sigma] / \Phi(\mathrm{k})\}^{1 / \gamma}-1$.

Proof:

Let $\lambda_{1}$ represent the compensating variation for truncating the distribution of $\ln z$; more precisely, $\lambda_{1}$ is the percentage change in consumption, uniform across all dates and values of shocks, required to leave the consumer indifferent between unrestricted variation in $\ln \mathrm{z}$ and variation in $\ln \mathrm{z}$ restricted to be greater than $-\mathrm{k} \sigma$. Including the compensating variation, the consumption process can be written as $c_{t}=\left(1+\lambda_{1}\right)\left(1+g_{1}\right)^{t}\left(\exp \left(-\sigma^{2} / 2\right)\right) z_{t}$. Substituting $c_{t}$ into the expression for expected discounted utility yields an indirect utility function, denoted as $\Psi\left(\lambda_{1}, \mathrm{~g}, \sigma^{2}\right)$ in the unrestricted case and as $\Psi(0, \mathrm{~g}$, restricted $\ln \mathrm{z})$ in the restricted case. Specifically,

$$
\begin{aligned}
\Psi\left(\lambda_{1}, g, \sigma^{2}\right) & =\underset{t=0}{E} \sum_{t=0}^{\infty} \beta^{t}(1 / \gamma)\left[\left(1+\lambda_{1}\right)(1+g)^{t}\left(\exp \left(-\sigma^{2} / 2\right)\right) z_{t}\right]^{\gamma} \\
& =(1 / \gamma)\left(1+\lambda_{1}\right)^{\gamma}\left(\exp \left(-\gamma \sigma^{2} / 2\right)\right) \underset{t}{E} \sum_{t=0}^{\infty} \beta^{t}(1+g)^{t \gamma} z_{t}^{\gamma} .
\end{aligned}
$$

As shown in Aitchison and Brown (1957), a property of a lognormal variable with $\mu=0$ is:

$\mathrm{Ez}^{\gamma}=\exp \left(\gamma^{2} \sigma^{2} / 2\right)$ if $\mathrm{z}$ is not truncated. Thus, the indirect utility function can be simplified to:

$$
\Psi\left(\lambda_{1}, \mathrm{~g}, \sigma^{2}\right)=(1 / \gamma)\left(1+\lambda_{1}\right)^{\gamma} \exp \left[-\gamma(1-\gamma) \sigma^{2} / 2\right] \sum_{\mathrm{t}=0}^{\infty} \beta^{\mathrm{t}}(1+\mathrm{g})^{\mathrm{t} \gamma} \text {. }
$$

Turning to the restricted case,

$\Psi(0, \mathrm{~g}$, restricted $\ln \mathrm{z})=(1 / \gamma) \exp \left(-\gamma \sigma^{2} / 2\right)\left[\Sigma \beta^{\mathrm{t}}(1+\mathrm{g})^{\mathrm{t} \gamma}\right]\left(\mathrm{Ez}_{\mathrm{t}}^{\gamma}\right)_{\text {restricted }}$.

But from lemma 1 (with $\mathrm{j}=\gamma$ ) and $\ln \mathrm{z}_{0}=-\mathrm{k} \sigma$,

$\left(\mathrm{Ez}_{\mathrm{t}}^{\gamma}\right)_{\text {restricted }}=\exp \left(\gamma^{2} \sigma^{2} / 2\right)\left\{(1-\Phi(-\mathrm{k}-\gamma \sigma)) /(1-\Phi(-\mathrm{k})\}=\exp \left(\gamma^{2} \sigma^{2} / 2\right)[\Phi(\mathrm{k}+\gamma \sigma) / \Phi(\mathrm{k})]\right.$,

making use of the relationship $1-\Phi(-x)=\Phi(x)$ for the standard normal distribution.

Substituting in this expression and then equating $\Psi(0, \mathrm{~g}$, restricted $\ln \mathrm{z})$ with $\Psi\left(\lambda_{1}, \mathrm{~g}, \sigma^{2}\right)$, we get:

$$
(1 / \gamma)(1+\lambda)^{\gamma} \exp \left[-\gamma(1-\gamma) \sigma^{2} / 2\right] \sum_{\mathrm{t}=0}^{\infty} \beta^{\mathrm{t}}(1+\mathrm{g})^{\mathrm{t} \gamma}=(1 / \gamma) \exp \left[-\gamma(1-\gamma) \sigma^{2} / 2\right]\left[\sum_{\mathrm{t}=0}^{\infty} \beta^{\mathrm{t}}(1+\mathrm{g})^{\mathrm{t} \gamma}\right][\Phi(\mathrm{k}+\gamma \sigma) / \Phi(\mathrm{k})]
$$

Cancellation of like terms from both sides and simplification yields the desired result:

$\lambda_{1}=\{\Phi[\mathrm{k}+\gamma \sigma] / \Phi(\mathrm{k})\}^{1 / \gamma}-1$. 
To fix ideas, suppose that it is feasible for policy to offset all draws for $\ln \mathrm{z}$ below its zero mean (or equivalently, all draws for $\mathrm{z}$ between 0 and 1). This corresponds to a value of $\mathrm{k}=0$ in proposition 1. In addition, let $r=5$ (or $\gamma=1-r=-4)$ and use the Lucas value for $\sigma$ of .013 . Given these parameter values, the compensating variation, $\lambda_{1}$, is .01 in our case of complete offset of below-trend movements of consumption, implying that individuals would give up 1 percent of consumption across the board. This is about 25 times larger than the amount that individuals would give up in the Lucas case of complete elimination of variance. The main reason for the quantitative difference is that the mean of consumption is unaffected by policy in the Lucas case but is increased in ours. From lemma 1 we see that, in our case, the pre- and post-policy mean values of $\mathrm{z}$ are related as follows:

$\mathrm{E}\left(\mathrm{z}_{\text {post }}\right)=\mathrm{E}\left(\mathrm{z}_{\text {pre }}\right)\{(1-\Phi(-\sigma)) /(1-\Phi(0))\}=2 \mathrm{E}\left(\mathrm{z}_{\text {pre }}\right)(1-\Phi(-\sigma))>\mathrm{E}\left(\mathrm{z}_{\text {pre }}\right)$

where we have made use of $\mathrm{k}=\mu=0$ and of the properties of the standard normal distribution. ${ }^{5}$ Substituting in the Lucas value of $\sigma(=.013)$, the post-policy mean is 1 percent higher than the pre-policy mean.

Another interesting issue is the value to individuals of policies that offset only "big" negative shocks rather than all negative shocks. If $\mathrm{k}=2$, then this amounts to seeking the value of eliminating negative shocks greater than two standard deviations from the mean. In this case, $\lambda_{1}=.0008$, roughly twice as large as the Lucas value of eliminating all variability, but still a small number. Again, the mean of $\mathrm{z}$ is increased by the truncation, but only 0.2 percent. The key reason for these small values is that post-war recessions generally have not been very severe, at least in comparison to the pre-war experience (and as reflected in a relatively small value for $\sigma$ in the post-war period). Indeed, Susanto Basu and Alan Taylor (1999) estimate that the standard deviation of log consumption was about three times larger in the period 1919 to 1939 than in the post World War II period. With the implied value for $\sigma(\approx .04)$, elimination of the great depression--modeled here as a $\mathrm{k}=2$ event--would be worth about 0.8 percent of consumption, ten times the value of the corresponding policy in the post-war period.

${ }^{5}$ For the sake of completeness, note that the variance of $\mathrm{z}$ declines in our case. Using lemma 1 and the Lucas value for $\sigma(=.013)$, the variance of $\mathrm{z}$ roughly is cut about 60 percent. There is a corresponding reduction in the variance of $\ln \mathrm{z}$ from $\sigma^{2}$ to $.36 \sigma^{2}$. 


\section{The Value of Eliminating Variation in a Plucking-style Model}

The thought experiment in the previous section is not without its problems. For example, if policy perfectly offsets all negative deviations from trend, ceteris paribus, then the resulting time series for consumption will have a new, higher, mean or trend line. But this implies the existence of negative deviations from the new trend line. So why not eliminate these new negative draws? This process conceivably would continue until the economy was always operating at its peak level.

One way to address this issue is to model macroeconomic activity as essentially asymmetric deviations from full-employment capacity or potential levels along the lines of the "plucking" model discussed in Milton Friedman (1993) and Daniel Sichel (1994). Indeed, there is mounting statistical evidence that such a framework is preferred to one of symmetrical cycles; for example, see Chang-Jin Kim and Charles Nelson (1999). We now consider an analytically tractable implementation of this idea.

Suppose that $\log$ consumption (or more precisely, $\ln z$ ) is a truncated normal variable with only the left half of the mean zero, normal distribution considered in the base case; that is, $\log$ consumption either can be at its maximum value or below. In this setup, what is the value to individuals of eliminating all negative realizations? Proposition 2 will provide an answer to this question. ${ }^{6}$ We turn now to a formal statement of the proposition; its proof depends on lemma 2 , which to our knowledge is a new result and is proved in the Appendix.

\section{Lemma 2}

If $\ln \mathrm{z} \sim \mathrm{N}\left(\mu, \sigma^{2}\right)$ and is truncated from above at $\ln \mathrm{z}_{0}$ (i.e., if the distribution of $\ln \mathrm{z}$ above $\ln z_{0}$ is removed), and if $\Phi($.$) denotes the standard normal distribution function, then$

$$
\begin{aligned}
E\left(z^{j}\right) & =(j t h \text { moment of } z \text { about zero if not truncated }) \times\left\{\left(\Phi\left(\Delta_{0}-j \sigma\right)\right) /\left(\Phi\left(\Delta_{0}\right)\right\}\right. \\
& =\exp \left[j \mu+j^{2} \sigma^{2} / 2\right] \times\left\{\left(\Phi\left(\Delta_{0}-j \sigma\right)\right) /\left(\Phi\left(\Delta_{0}\right)\right\}\right.
\end{aligned}
$$

where $\Delta_{0}=\left(\ln \mathrm{z}_{0}-\mu\right) / \sigma$.

${ }^{6}$ The comparability of the compensating variations derived in Propositions 1 and 2 is addressed below. 


\section{Proposition 2}

$\infty$

As in proposition 1, suppose consumers maximize $E\left\{\Sigma \beta^{t} U\left(c_{t}\right)\right\}$ where $U\left(c_{t}\right)=c_{t}^{\gamma} / \gamma$ $\mathrm{t}=0$

and that $c_{t}=(1+g)^{t}\left(\exp \left(-\sigma^{2} / 2\right)\right) z_{t}$, where $\ln z_{t}$ is a normal variable truncated from above at its mean of 0 . The value (compensating variation) to an individual of eliminating all negative deviations of $\ln \mathrm{z}$ from zero (that is, the value of maintaining log consumption at its maximum feasible level) is given by:

$\lambda_{2}=\left\{(1 / 2)^{1 / \gamma} \exp \left[(1-\gamma) \sigma^{2} / 2\right]\right\} /[\Phi(-\sigma \gamma)]^{1 / \gamma}-1$

Proof:

Let $\lambda_{2}$ be the percentage change in consumption, uniform across all dates and values of shocks, required to leave the consumer indifferent between a world in which $\ln \mathrm{z}$ is restricted to be less than the zero mean and one in which all negative deviations of $\ln \mathrm{z}$ from zero are eliminated. The consumption process can be written as $c_{t}=\left(1+\lambda_{2}\right)(1+g)^{t}\left(\exp \left(-\sigma^{2} / 2\right)\right) z_{t}$, including the compensating variation. Substituting $c_{t}$ into the expression for expected discounted utility yields an indirect utility function, denoted as $\Psi\left(\lambda_{2}, \mathrm{~g}, \sigma^{2}\right)$ in the benchmark case (where $\ln \mathrm{z}$ is truncated from above at its zero mean), and as $\Psi(0, \mathrm{~g}, 0)$ in the alternative case (no negative deviations of $\ln \mathrm{z}$, so that $\sigma=0)$. Using lemma 2 with $\mathrm{j}=\gamma$ and $\Delta_{0}=0, \mathrm{E}\left(\mathrm{z}^{\gamma}\right)=\left[\exp \left(\gamma^{2} \sigma^{2} / 2\right)\right][\Phi(-\gamma \sigma) / \Phi(0)]$, and we get:

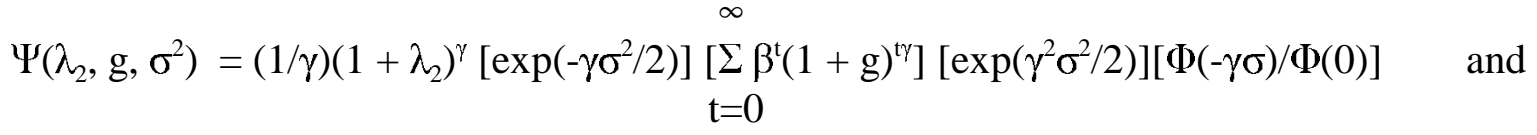
$\infty$

$\Psi(0, \mathrm{~g}, 0)=(1 / \gamma)\left[\Sigma \beta^{\mathrm{t}}(1+\mathrm{g})^{\mathrm{t} \gamma}\right]$ $\mathrm{t}=0$

Equating these two expressions and simplifying (and using $\Phi(0)=0.5$ ) yields:

$\left(1+\lambda_{2}\right)^{\gamma}\left[\exp \left(-\gamma(1-\gamma) \sigma^{2} / 2\right)\right][\Phi(-\gamma \sigma) / 0.5]=1$. Further simplification yields the final result: $\lambda_{2}=\left\{(1 / 2)^{1 / \gamma} \exp \left[(1-\gamma) \sigma^{2} / 2\right]\right\} /[\Phi(-\gamma \sigma)]^{1 / \gamma}-1$

Again to fix ideas, let $r=5(\gamma=-4)$ and $\sigma=.013$. For these parameter values, $\lambda_{2}=.0105$, that is, consumers would willingly surrender about 1.05 percent of their consumption across the board in order to avoid any negative plucking; this is 25 times larger than the Lucas estimate of the value of complete elimination of variance in a world of symmetric cycles. Also, the mean value of $z$ rises as a result of the policy that eliminates asymmetrical variation. Prior to the policy, $E(z)$ is determined from lemma 2; setting $\mathrm{j}=1, \sigma=.013$, and $\Delta_{0}=0$, we have that 
$\mathrm{E}(\mathrm{z})=.99$. Following the policy (that is, when $\sigma=0$ ), we have that $\mathrm{E}(\mathrm{z})=1$. Thus the mean of $\mathrm{z}$ rises about 1 percent.

It is important to recognize that the compensating variation calculation based on proposition $2\left(\lambda_{2}\right)$ is not directly comparable to those based on proposition $1\left(\lambda_{1}\right)$ or Lucas $\left(\lambda_{L}\right)$, because the underlying view of macroeconomic fluctuations is fundamentally different (although we introduce a trick below that allows $\lambda_{1}$ and $\lambda_{2}$ to be compared). Indeed, the compensating variation estimate based on proposition 2 stands on its own, and it is the value of complete stabilization if macroeconomic fluctuations in the United States are best modeled using the plucking framework. As such, $\lambda_{2}$ is comparable to other welfare calculations such as the value of eliminating product market monopolies or distorting taxes (just as $\lambda_{1}$ and $\lambda_{\mathrm{L}}$ are comparable if macroeconomic fluctuations are symmetric).

In the remainder of this section it will be argued that the compensating variation computed using proposition 2 likely needs to be increased to make it directly comparable to the compensating variations in proposition 1 and in Lucas; that is, the compensating variation in proposition 2 is at least 25 times greater than the Lucas value. We begin by noting that in proposition 1 , with $\mathrm{k}=0$, complete elimination of negative deviations from the mean still leaves open the virtual certainty of performance that would be viewed as below peak or capacity in the sense of proposition 2 (and leaves open the low probability of "above-capacity" outcomes owing to the unboundedness of a lognormally distributed variable), whereas in proposition 2 complete elimination of down-plucks leaves the economy always at capacity. Thus people should be happier with the latter outcome, yet the compensating variations are about the same (that is, $\lambda \approx .01$ in each case).

A simple and straightforward way to make the results comparable is to redefine the consumption process in proposition 2 as follows: $c_{t}=P(1+g)^{t}\left(\exp \left(-\sigma^{2} / 2\right)\right) z_{t}$ where $P>1$. Think of $\mathrm{P}(1+\mathrm{g})^{\mathrm{t}}$ as representing the peak or maximum potential level of consumption. ${ }^{7}$ Of course, as

${ }^{7}$ Recall in proposition 2 that $\ln \mathrm{z}$ is truncated from above at zero or, equivalently, at $\mathrm{z}=1$. With all negative deviations from this truncation value eliminated $(\sigma=0), c_{t}=P(1+g)^{t}$. Also, the formula for $\lambda_{2}$ would be unaffected if the alternative consumption process had been assumed, because $\mathrm{P}^{\gamma}$ would cancel from both sides of $\Psi\left(\lambda_{2}, \mathrm{~g}, \sigma^{2}\right)=\Psi(0, \mathrm{~g}, 0)$ in the proof. 
mentioned earlier, consumption theoretically is unbounded in our models. However, as a conservative estimate, assume that the peak level of consumption is about 2.5 standard deviations above the mean value $\left[=(1+g)^{t}\right]$ of proposition 1 ; because the standard deviation of consumption is approximately .013, it follows that $\mathrm{P} \approx 1.03{ }^{8}$ That is, the peak level of consumption is taken to be roughly 3 percent above the mean value of proposition 1 .

We now determine the value to individuals of switching from the symmetrical world of proposition 1 with $\mathrm{k}=0$ to the asymmetrical world of proposition 2 with $\sigma=0$. Of course, such a switch is purely hypothetical because the actual economy's behavior is characterized either one way or the other; the hypothetical switch is simply a means allowing us to compare the various compensating variations. We will show that the value of the switch is positive, implying that the compensating variation computed in proposition $2\left(\lambda_{2} \approx .01\right)$ is even larger when made comparable to the compensating variation in proposition 1 with $\mathrm{k}=0$ and, by implication, to the Lucas estimate of the value of eliminating variance in a symmetrical world. To see this, solve for $\lambda$ in the following equation:

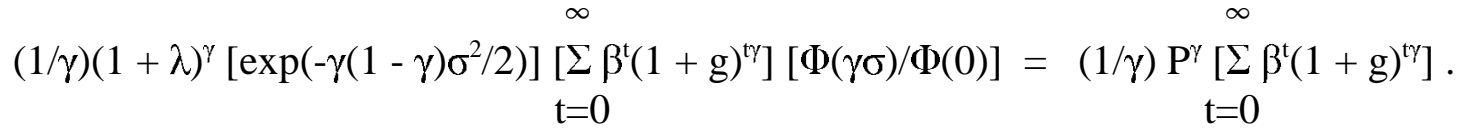

The left-hand side is the indirect utility function (including the compensating variation) when $\ln \mathrm{z}$ is restricted to be non-negative in the symmetrical world (the $\mathrm{k}=0$ case in proposition 1) and the right-hand side is the indirect utility function when there are no negative deviations of $\ln \mathrm{z}$ from capacity (the $\sigma=0$ case in proposition 2 together with the modified consumption process). Simplifying, we get:

$\lambda=\mathrm{P}\left[\exp \left(-\gamma(1-\gamma) \sigma^{2} / 2\right)\right][\Phi(0) / \Phi(\gamma \sigma)]^{1 / \gamma}-1$.

For $\mathrm{P}=1.03, \gamma=-4$, and $\sigma=.013$, we have that $\lambda=.02$, implying that individuals would give up 2 percent of consumption across the board. Thus, by showing that this compensating variation is positive, we have established that the value of eliminating all negative plucks is in fact an even larger multiple of the Lucas estimate of the value of complete elimination of variance in a

8 This result uses the value of the standard deviation of log consumption, $\sigma=.013$; it also uses the formula for the standard deviation of a lognormally distributed random variable $\mathrm{z}$, $\left[\exp \left(\sigma^{2}\right)\right]\left[\left(\exp \left(\sigma^{2}\right)-1\right]^{1 / 2}\right.$. 
symmetrical world than was the case in proposition 2.

\section{The Value of Increasing the Growth Rate of Consumption}

In this section the value of a permanent increase in the growth rate of consumption $(\mathrm{g})$ is determined. The valuation formula derived below in proposition 3 differs from that in Lucas and implies a smaller gain from increasing the growth rate. The key analytic difference is that variation in the coefficient of relative risk aversion affects the compensating variation, whereas this is not the case in the Lucas formula. Indeed, his formula is based on the unstated assumption that the coefficient of relative risk aversion is exactly unity; for any other value, his formula is not valid. A formal statement and proof of our result follows.

\section{Proposition 3}

Following Lucas, suppose consumers maximize $E\left\{\Sigma \beta^{t} U\left(c_{t}\right)\right\}$ where $U\left(c_{t}\right)=c_{t}^{\gamma} / \gamma$. $\mathrm{t}=0$

Here, $\gamma=1-r$ and $r>1$. Also assume that $c_{t}=(1+g)^{t}\left(\exp \left(-\sigma^{2} / 2\right)\right) z_{t}$ where $\ln z_{t} \sim N\left(0, \sigma^{2}\right)$. The value to individuals of changing the growth rate from $\mathrm{g}_{0}$ to $\mathrm{g}_{1}$ is given by:

$\lambda_{3}=\left\{\left[1-\beta\left(1-\mathrm{g}_{1}\right)^{\gamma}\right] /\left[1-\beta\left(1-\mathrm{g}_{0}\right)^{\gamma}\right]\right\}^{1 / \gamma}-1$.

Proof:

Let $\lambda_{3}$ represent the compensation for variation in the growth rate from $\mathrm{g}_{0}$ to $\mathrm{g}_{1}$; more precisely, $\lambda_{3}$ is the percentage change in consumption, uniform across all dates and values of shocks, that is required to leave the consumer indifferent between the growth rates $g_{0}$ and $g_{1}$. Thus, the consumption process can be written as $c_{t}=\left(1+\lambda_{3}\right)\left(1+g_{1}\right)^{t}\left(\exp \left(-\sigma^{2} / 2\right)\right) z_{t}$ under the alternative growth rate. Substituting $c_{t}$ into the expression for expected discounted utility yields an indirect utility function, denoted as $\Psi\left(\lambda_{3}, \mathrm{~g}_{1}, \sigma^{2}\right)$ in the alternative case and as $\Psi\left(0, \mathrm{~g}_{0}, \sigma^{2}\right)$ in the base case. Equating these expressions yields:

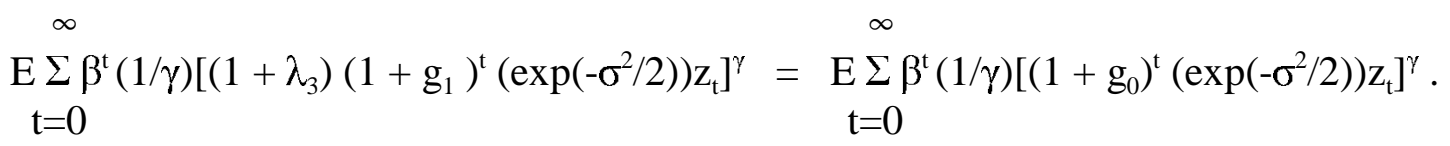

Cancellation of like terms from both sides yields (and making use of the stationarity of $\mathrm{z}_{\mathrm{t}}$ ):

$$
\begin{aligned}
& \sum_{\mathrm{t}=0}^{\infty} \beta^{\mathrm{t}}\left(1+\lambda_{3}\right)^{\gamma}\left(1+\mathrm{g}_{1}\right)^{\mathrm{t} \gamma}=\sum_{\mathrm{t}=0}^{\infty} \beta^{\mathrm{t}}\left(1+\mathrm{g}_{0}\right)^{\mathrm{t} \gamma} . \quad \text { Simplifying, we get: } \\
& \left(1+\lambda_{3}\right)^{\gamma}=\sum_{\mathrm{t}=0}^{\infty} \beta^{\mathrm{t}}\left(1+\mathrm{g}_{0}\right)^{\mathrm{t} \gamma} / \sum_{\mathrm{t}=0}^{\infty} \beta^{\mathrm{t}}\left(1+\mathrm{g}_{1}\right)^{\mathrm{t} \gamma}
\end{aligned}
$$


Assuming $\gamma<0$ (or $r>1$ ) and $g_{i}>0$, and since $\beta \in(0,1)$, it follows that $\beta\left(1+g_{i}\right)^{\gamma}<1$ for $i=0,1$. Thus, from the properties of convergent geometric series,

$$
\infty
$$$$
\sum \beta^{t}\left(1+g_{i}\right)^{t \gamma}=1 /\left[1-\beta\left(1+g_{i}\right)^{\gamma}\right] \quad \text { for } \mathrm{i}=0,1 \text { Hence, }
$$$$
\mathrm{t}=0
$$$$
\lambda_{3}=\left\{\left[1-\beta\left(1+g_{1}\right)^{\gamma}\right] /\left[1-\beta\left(1+g_{0}\right)^{\gamma}\right]\right\}^{1 / \gamma}-1
$$

To get a sense of the magnitudes involved, suppose the growth rate rises from 3 percent to 4 percent per annum. With $\beta=.95$ and $r=5, \lambda_{3}=-.046$; that is, individuals would give up about 4-1/2 percent of their consumption across the board in order to obtain the higher growth rate. This is significantly smaller than the 17 percent figure derived by Lucas. As another example, the value of increasing the growth rate only one-tenth of one percentage point (to 3.1 percent per annum) is about -.005 or about $1 / 2$ percent of consumption across the board.

Thus, the value of a one-tenth of one percentage point permanent increase in the consumption growth rate is about 10 times greater than the value of completely eliminating consumption variance in a world of symmetrical cycles; using the Lucas formulas, the value of the former is about 50 times greater than the value of the latter. ${ }^{9}$

\section{Conclusion}

Pulling together the various results, the value of elimination of all below-trend movements in consumption in a world of symmetrical cycles, or elimination of all belowcapacity movement in the "plucking" world, is at least 25 times greater than the value of complete elimination of consumption variance in the symmetric Lucas case. The main reason for the quantitative difference is that the mean of consumption is unaffected by policy in the Lucas case but is increased in ours.

Moreover, we find the value of increases in the growth rate of consumption to be smaller than the value in Lucas by a factor of about four, although still relatively large. Indeed, we find

9 The careful reader will note that proposition 3 is premised on $r>1$. In fact, as noted earlier, if and only if $r=1$ (logarithmic preferences), then the Lucas formula is true, and the compensating variation, $\lambda$, is independent of the coefficient of relative risk aversion. However, as Lucas notes, people appear to be more risk-averse than is implied by the $r=1$ case. Indeed, empirical estimates of $r$ typically well exceed unity. 
that the value of stabilization relative to the value of higher growth is at least 100 times larger than the corresponding figure in Lucas. Taken together these results suggest that even a small permanent increase in the growth rate of consumption is worth a lot, but--in contrast to Lucas-so too is stabilization in the alternative senses analyzed here.

While the quantitative analysis of this paper suggests that boosting growth and eliminating downside variation of consumption would provide sizable value ex ante to individuals, there is still the open issue of whether policies achieving these goals can be found and implemented at low cost. 


\section{APPENDIX}

In the appendix we prove lemmas 1 and 2. We note that proof of a theorem on moments of a lognormal distribution truncated from below is found in Aitchison and Brown (1957). This theorem is quite similar to our lemma 1; the former is stated in terms of the lognormal distribution function, while the latter is stated in terms of the standard normal distribution. Lemma 2 appears to be a completely new result.

We initially note that the log normal distribution function, $\Lambda($.$) , and the normal$ distribution function, $\mathrm{N}($.$) , are related as: \Lambda(\mathrm{x})=\mathrm{N}(\ln \mathrm{x})$ by definition (with $\mathrm{x}>0$ ). We assume below that the mean of $\ln x$ is $\mu$ and the variance is $\sigma^{2}$. The standard normal distribution function is defined as $\Phi($.$) . Finally, we note that \Lambda\left(\mathrm{x} \mid \mu, \sigma^{2}\right)=\mathrm{N}(\ln \mathrm{x})=\Phi[(1 / \sigma) \ln \mathrm{x}+(-\mu / \sigma)]$ for $\mathrm{x}>0$.

Proof of both lemmas depends crucially on the following definition and theorem; the theorem is proved in Aitchison and Brown (1957, Chapter 2).

Definition: The jth (or "incomplete" jth) moment distribution function of $\Lambda\left(\mu, \sigma^{2}\right)$ is defined by: $\Lambda_{\mathrm{j}}\left(\mathrm{x} \mid \mu, \sigma^{2}\right)=\left(1 / \lambda_{\mathrm{j}}\right) \int_{0}^{\mathrm{x}} \mathrm{v}^{\mathrm{j}} \mathrm{d} \Lambda\left(\mathrm{v} \mid \mu, \sigma^{2}\right)$. In this definition, $\Lambda\left(\mathrm{x} \mid \mu, \sigma^{2}\right)$ denotes the distribution function of the lognormally distributed variable $x$; $\lambda_{\mathrm{j}}$ denotes the $\mathrm{jth}$ moment of $\mathrm{x}$ about the origin and--as is well known--equals $\exp \left(j \mu+\mathrm{j}^{2} \sigma^{2} / 2\right)$.

Theorem: The jth moment distribution of the $\Lambda$-distribution with parameters $\mu$ and $\sigma^{2}$ is also a $\Lambda$-distribution with parameters $\mu+\mathrm{j} \sigma^{2}$ and $\sigma^{2}$ respectively; that is, $\Lambda_{\mathrm{j}}\left(\mathrm{x} \mid \mu, \sigma^{2}\right)=\Lambda\left(\mathrm{x} \mid \mu+\mathrm{j} \sigma^{2}, \sigma^{2}\right)$.

With these results in hand, we restate each lemma along with proofs.

\section{Lemma 1}

If $\ln \mathrm{z} \sim \mathrm{N}\left(\mu, \sigma^{2}\right)$ and is truncated from below at $\ln \mathrm{z}_{0}$ (i.e., if the distribution of $\ln \mathrm{z}$ below $\ln z_{0}$ is removed), and if $\Phi($.$) denotes the standard normal distribution function, then$

$$
\begin{aligned}
E\left(z^{j}\right) & =(j t h \text { moment of } z \text { about zero if not truncated }) \times\left\{\left(1-\Phi\left(\Delta_{0}-j \sigma\right)\right) /\left(1-\Phi\left(\Delta_{0}\right)\right\}\right. \\
& =\exp \left[j \mu+j^{2} \sigma^{2} / 2\right] \times\left\{\left(1-\Phi\left(\Delta_{0}-j \sigma\right)\right) /\left(1-\Phi\left(\Delta_{0}\right)\right\},\right.
\end{aligned}
$$

where $\Delta_{0}=\left(\ln \mathrm{z}_{0}-\mu\right) / \sigma$

Proof:

Using the above theorem, Aitchison and Brown (1957, Chapter 9) prove that: 
$E\left(z^{j}\right)=\exp \left[j \mu+j^{2} \sigma^{2} / 2\right]\left\{\left(1-\Lambda\left(\xi \mid \mu+j \sigma^{2}, \sigma^{2}\right)\right) /\left(1-\Lambda\left(\xi \mid \mu, \sigma^{2}\right)\right)\right\}$.

Now let $\xi=\ln \mathrm{z}_{0}=\mathrm{x}$ and apply the result noted above that $\Lambda\left(\mathrm{x} \mid \mu, \sigma^{2}\right)=\Phi[(1 / \sigma) \ln \mathrm{x}+(-\mu / \sigma)]$. This completes the proof.

\section{Lemma 2}

If $\ln \mathrm{z} \sim \mathrm{N}\left(\mu, \sigma^{2}\right)$ and is truncated from above at $\ln \mathrm{z}_{0}$ (i.e., if the distribution of $\ln \mathrm{z}$ above $\ln z_{0}$ is removed), and if $\Phi($.$) denotes the standard normal distribution function, then$

$\mathrm{E}\left(\mathrm{z}^{\mathrm{j}}\right)=(\mathrm{jth}$ moment of $\mathrm{z}$ about zero if not truncated $) \times\left\{\left(\Phi\left(\Delta_{0}-\mathrm{j} \sigma\right)\right) /\left(\Phi\left(\Delta_{0}\right)\right\}\right.$

$$
=\exp \left[\mathrm{j} \mu+\mathrm{j}^{2} \sigma^{2} / 2\right] \times\left\{\left(\Phi\left(\Delta_{0}-\mathrm{j} \sigma\right)\right) /\left(\Phi\left(\Delta_{0}\right)\right\}\right.
$$

where $\Delta_{0}=\left(\ln \mathrm{z}_{0}-\mu\right) / \sigma$

Proof:

The specification of the distribution of a lognormal distribution truncated from above at $\xi$ is:

$\operatorname{Prob}\{\mathrm{X} \leq \mathrm{X}\}=0 \quad(\mathrm{x} \geq \xi)$ and

$\operatorname{Prob}\{\mathrm{X} \leq \mathrm{x}\}=\left[\Lambda\left(\mathrm{x} \mid \mu, \sigma^{2}\right)\right] /\left[\Lambda\left(\xi \mid \mu, \sigma^{2}\right)\right] \quad(0<\mathrm{x}<\xi)$.

The jth moment about zero is given by:

$\mathrm{E}\left(\mathrm{X}^{\mathrm{j}}\right)=\int_{0}^{\xi}\left[\mathrm{x}^{\mathrm{j}} / \Lambda\left(\xi \mid \mu, \sigma^{2}\right)\right] \mathrm{d} \Lambda\left(\mathrm{x} \mid \mu, \sigma^{2}\right)=\lambda_{\mathrm{j}} \Lambda_{\mathrm{j}}\left(\mathrm{x} \mid \mu, \sigma^{2}\right) / \Lambda\left(\xi \mid \mu, \sigma^{2}\right)$

where the second equality follows from the definition of the jth moment distribution. But from the above theorem and the expression for $\lambda_{\mathrm{j}}$, we get:

$E\left(X^{j}\right)=\left[\exp \left(j \mu+j^{2} \sigma^{2} / 2\right)\right] \Lambda\left(x=\xi \mid \mu+j \sigma^{2}, \sigma^{2}\right) / \Lambda\left(\xi \mid \mu, \sigma^{2}\right)$.

Let $\mathrm{X}=\mathrm{z}$ and $\xi=\ln \mathrm{z}_{0}$; also apply the result noted above that $\Lambda\left(\mathrm{x} \mid \mu, \sigma^{2}\right)=\Phi[(1 / \sigma) \ln \mathrm{x}+(-\mu / \sigma)]$. We obtain the desired result:

$E\left(z^{j}\right)=\left[\exp \left(j \mu+j^{2} \sigma^{2} / 2\right)\right]\left\{\left(\Phi\left(\Delta_{0}-j \sigma\right)\right) /\left(\Phi\left(\Delta_{0}\right)\right\}\right.$

where $\Delta_{0}=\left(\ln z_{0}-\mu\right) / \sigma$. 


\section{References}

Aitchison, J. and J. A. C. Brown. The Lognormal Distribution. Cambridge: Cambridge University Press, 1957.

Atkeson, Andrew, and Christopher Phelan. "Reconsidering the Costs of Business Cycles with Incomplete Markets," NBER Macroeconomics Annual 1994, National Bureau of Economic Research, 1994, pp. 187-207.

Basu, Susanto, and Alan Taylor. "Business Cycles in International Historical Perspective," NBER Working Paper No. 7090, April 1999.

Blinder, Alan. "Keynes, Lucas, and Scientific Progress," American Economic Review, May 1987, pp. 130-136.

Caballero, Ricardo. "Aggregate Investment," Chapter 12 in Handbook of Macroeconomics, edited by John Taylor and Michael Woodford. Amsterdam: Elsevier, 1999.

De Long, J. Bradford, and Lawrence Summers. "How Does Macroeconomic Policy Affect Output?” Brookings Papers on Economic Activity, 1988, pp. 433-480.

Friedman, Milton. “The Plucking Model of Business Fluctuations Revisited,” Economic Inquiry, April, 1993, pp. 171-177.

Imrohoroglu, Ayse. "Cost of Business Cycles with Indivisibilities and Liquidity Constraints," Journal of Political Economy 97(6), 1989, pp. 1364-1383.

Kim, Chang-Jin, and Charles Nelson. "Friedman's Plucking Model of Business Fluctuations: Tests and Estimates of Permanent and Transitory Components," Journal of Money, Credit, and Banking, August 1999.

Lucas, Robert. Models of Business Cycles. New York: Basil Blackwell, 1987.

Otrok, Christopher. "On Measuring the Welfare Cost of Business Cycles," Mimeo, University of Iowa, November 1998.

Romer, Christina. "Changes in Business Cycles: Evidence and Explanations," Journal of Economic Perspectives, Spring 1999, pp. 23-44.

Sichel, Daniel. "Inventories and the Three Phases of the Business Cycle," Journal of Business and Economic Statistics, vol. 12, 1994, pp. 269-277.

Tobin, James. “Comment," NBER Macroeconomics Annual 1994, National Bureau of Economic Research, 1994, pp. 212-216. 